REFERENCES

Allen, F. H., jun., Diamond, L. K., and Watrous, J. B., jun. (1949). New Engl. J. Med., 241, 799.

Carter, B. B. (1949). J. Immunol., 61, 79.

- (1954). Lancet. 2 ,

avies, B. S.. Gerrard, J., Hachuel, W. L. F., and Howarth, B. E. (1953) Bgham med. Rev., 18, 77.

Diamond. L. K. (1947). Proc. roy. Soc. Med., 40, 546

- (1948). Pediatrics, 2, 520

Allen, F. H., Jun., and Thomas, W. O. jun. (1951), New Engl. J. Med., 244. 39.

Allen, F. H., jun., Vann, D. D., and Powers, J. R. (1952). Ibid.,

Field, C. M. B., and Hawkins, E. (1951). British Medical Journal, 1, 950.

Hardwick, C. Bnd Lloyd O (1941) Lancet 2 339.

Hart, A. P. (1925). Canad. med. A ss. J., 15, 1008.

Henderson J (1950) Cancet, 291 .

Homburger, F. (1946). Proc. Soc. exp. Biol. (N.Y.), 61, 101

Kariher D H and Miller D. I (1947). Amer J Obstet Gynec 54.

Miller G McCord A. B. Joos, H A and Clausen S. W (1952). J. Dis. Child., 84, 637.

Mollison, P. L. (1951) Blood Transfusion in Clinical Medicine. Blackwells Scientific Publications, Oxford.

and Cutbush, M. (1948) Lancet, 2,522.

- and Walker, W. (1952). Lancet, 2, 522.

Pickles, M. M. (1949). Haemolytic Disease of the Newborn. Blackwells Scientific Publications, Oxford.

Pinkus, L. R. (1948). J. Pediat., 33, 418.

Sacks, M. S., Spurling, C. L., Brass, I. D. J., and Jahn, E. F. (1950). Pediatrics, 6, 772 .

Van Loghem, J. J., and Bartels, H. L. J. M. (1949). British Medical Journal, 2, 160

Veall, N., and Mollison, P. L. (1950). Lancet, 2, 792.

Walker, W. (1950). Thesis for the Degree of Doctor of Medicine, University of Durham

and Murray, S. (1954). British Medical Journal, 2, 126.

Wallerstein. H. (1946). Lancet. 2, 922.

- (1947). Amer. J. Dis. Child., 73, 19

- (1948). Blood, Special Issue, No. 2, p. 170

Wiener, A. S., and Wexler, I. B. (1946). J. Lab. clin. Med., 31, 1016. (1949). Blood, 4,

1951). Pediatrics, 8, 117

- - and Grundfast, T. H. (1947). Bull. N.Y. Acad. Med., 23, 207.

\section{A STUDY OF THE ACTION OF TRICYCLAMOL CHLORIDE}

BY

PAMELA AYLETT, M.B., B.S., D.C.H. Research Fellow, Guy's Hospital

AND

\section{A. H. DOUTHWAITE, M.D., F.R.C.P. Senior Physician, Guy's Hospital}

In the search for efficient treatment of gastric and duodenal ulcer the primary object of prolonged reduction of free $\mathrm{HCl}$ concentration in the gastric juice has been achieved (Douthwaite and Thorne, 1954). It was postulated that the failure of single large doses of antacids was due to their rapid expulsion from the stomach, especially in cases of duodenal ulceration. Drugs which will reduce the rate of emptying should therefore prolong the antacid effect; at present this is obtainable only by the slow sucking of alkaline or buffering tablets. The difficulty of controlling nocturnal secretion might in this way be overcome.

The belladonna alkaloids and, to a far greater extent, hexamethonium (Douthwaite and Thorne, 1951) by injection, have been used for this purpose.

The object of this communication is to report our experiences with tricyclamol chloride (DL- $N$ methyl-3-cyclohexyl-3-hydroxy-3-phenylpropyl pyrrolidinium chloride), shown in animal experiments to have an antispasmodic and parasympatholytic action. It is an odourless crystalline substance, which is freely soluble in water. It may be given by mouth or by subcutaneous injection. The doses employed have varied from 25 to $100 \mathrm{mg}$. and are indicated in respect of each experiment.
Our object has been to test the effect on gastric and duodenal motility and tone; the influence on gastric acidity ; and the effect of a single dose of antacid on the $p \mathrm{H}$ of the gastric juice during the action of tricyclamol.

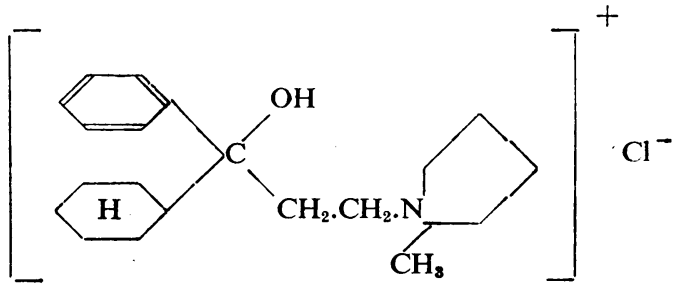

Tricyclamol chloride

\section{Methods}

The effects of tricyclamol upon gastric and duodenal motility were observed on the $x$-ray screen during a barium meal and films were taken. Comparison was made with barium meals given without the drug. The influence of tricyclamol on gall-bladder emptying was shown by cholecystography with and without a dose of tricyclamol.

The effect of tricyclamol on the $p \mathrm{H}$ and levels of free and total acid of test-meal samples were observed and compared with control meal samples obtained without the drug. In three patients tricyclamol was given immediately after passing a Ryle tube $-50 \mathrm{mg}$. intramuscularly in two cases and $50 \mathrm{mg}$. orally in one case. The meal was eaten and samples of gastric contents were taken every 15 minutes. In a fourth patient $100 \mathrm{mg}$. of tricyclamol was given orally half an hour before starting the meal.

Two of the patients also received an alkaline mixture (aluminium hydroxide gel B.P.C., $8 \mathrm{ml}$.) immediately after swallowing the meal. The stomach was not emptied of its resting contents. We wished to discover how effective tricyclamol might be in reducing the acidity of gastric contents under ordinary conditions, since, in actual treatment of peptic ulcer, drugs given to decrease acidity are used in the presence of some secretions still in the stomach. To be of value the drug should reduce acidity in the presence of previously secreted gastric juice.

Three of the four patients were given a "standard breakfast " of one boiled egg, two slices of toast, and two cupfuls of tea. Such a meal allows the response of the stomach to normal food to be measured in terms of $p \mathrm{H}$ and acidity, and probably represents a more usual gastric stimulus than a gruel meal. It has the disadvantage of not being directly comparable to series of test meals done in the past, when gruel was commonly used for the meal. One of these four patients received a gruel meal.

In an attempt to reduce sampling error (James and Pickering, 1949), about $30 \mathrm{ml}$. of gastric contents was aspirated at each time. After agitation of the syringe contents, about $7 \mathrm{ml}$. of the mixture was retained and the remainder returned to the stomach: $5 \mathrm{ml}$. of each sample was titrated within 24 hours of collection. (Storage at $4^{\circ} \mathrm{C}$. before the estimations.) The $p \mathrm{H}$ was measured electrometrically. Titration to $p \mathrm{H} 3$ with $0.5 \mathrm{~N} \mathrm{NaOH}$ solution was taken to represent the level of free acid in the samples. The level of total acid was measured by titration to $p \mathrm{H} 7$.

\section{Results}

1. Effect on Gastric and Duodenal Motility and Tone.Radiological observation of barium meals showed that gastric, duodenal, and small-intestinal motility and tone were considerably reduced after a dose of tricyclamol. (Figs. 1 and 2 show typical appearances.) Yet in a patient with a partial gastrectomy and symptoms of the "dumping syndrome" emptying of the stomach occurred even more rapidly than usual when $50 \mathrm{mg}$. of tricyclamol was given intramuscularly before a barium meal. This was associated with extreme flaccidity of the stomach, very well seen on 


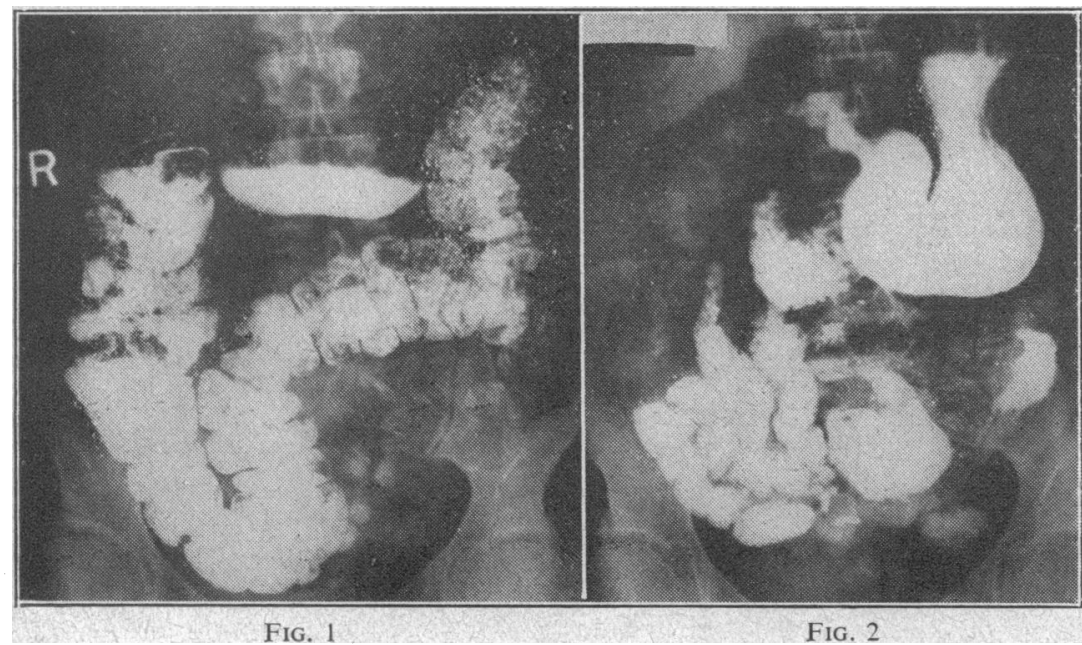

Fig. 1.-Control. Four hours after barium meal. Fig. 2.-The same patient as in Fig. 1. Four hours after barium meal. Tricyclamol chloride, $25 \mathrm{mg}$., was given intramuscularly 20 minutes before the meal.

screening. In a patient in whom a cholecystogram was done the gall-bladder emptied somewhat more slowly after $50 \mathrm{mg}$. of intramuscular tricyclamol, given half an hour before a fatty meal, than in a control cholecystogram. A little dye could still be seen in the gall-bladder three hours after the fatty meal, while in control films the gall-bladder was empty two hours after the fatty meal.

2. Influence on Gastric Acidity.-In two patients, $50 \mathrm{mg}$. of tricyclamol given intramuscularly produced some rise in $p \mathrm{H}$. This effect was short-lived and of relatively small degree. Free acid was again present after one hour in one case and after three-quarters of an hour in the other, a man with a gastro-enterostomy for many years recently complicated by a stomal ulcer. In these two cases intramuscular tricyclamol caused little change in the level of total acid, but there was a slight fall in one of the patients.

3. Effect of Single Dose of Antacid on $\mathrm{pH}$ iof Gastric Juice During Action of Tricyclamol.-Two patients received tricyclamol tablets by mouth. A dose of aluminium hydroxide gel was given as soon as the meal had been eaten. One patient receiving $50 \mathrm{mg}$. of tricyclamol and $8 \mathrm{ml}$. of aluminium hydroxide gel showed a moderate rise in $p H$. Free acid was absent for $1 \frac{1}{4}$ hours and then returned in relatively low concentration. There was a smaller fall in total acidity. Another patient was given $100 \mathrm{mg}$. of tricyclamol by mouth with the additional dose of alkaline mixture. In this case there was a greater rise in $p \mathrm{H}$. Free acid was absent for $2 \frac{1}{2}$ hours and then returned and increased in amount. There was a slight reduction in total acidity (see Fig. 3).

Uncomfortable dryness of the mouth, dilated pupils, and blurring of print on reading were noticed in most of the patients. These effects seemed more pronounced after the intramuscular than after the oral use of the drug. In one patient who had $50 \mathrm{mg}$. of tricyclamol orally no side-effects were observed.

\section{Discussion}

Tricyclamol chloride has a marked effect in reducing the motility of the stomach and duodenum, and to a far greater extent than the results produced by hyoscyamine (Douthwaite, 1947). This action may be of value in controlling the pain of peptic ulceration, since it is likely that the pain, at least in part, is due to spasm. Certainly, in the patient with gastro-enterostomy and stomal ulcer, already mentioned, quite severe pain was relieved after repeated oral doses of $50 \mathrm{mg}$. of the drug.

Tricyclamol has been shown to have some effect in reducing the concentration of free acid in gastric contents after a meal of normal food or gruel. This might be due to diminished secretion of acid juice, or to delay in gastric emptying with a resulting larger volume of gastric contents to dilute gastric secretion, or there might be a combination of both factors.

However, the change in the level of free acid was not marked nor long-lasting when tricyclamol was given alone. and seemed too small to be of much value of itself in the treatment of peptic ulcer. There might be some additional pain-relieving effect due to the association of this factor with the much more powerful spasmolytic action of tricyclamol. Given with an alkaline mixture, tricyclamol potentiated to a certain extent the fall in the level of free acid shown to be due to alkali alone (Douthwaite, 1939). A dose of $100 \mathrm{mg}$. orally was more effective than $50 \mathrm{mg}$. Such a combination might assist the process of healing in which free hydrochloric acid is undoubtedly a deterrent factor. It is suggested that a combination of $100 \mathrm{mg}$. of tricyclamol chloride by mouth with a full dose of antacid might go some way towards overcoming the difficulty hitherto experienced in controlling nocturnal secretion in the treatment of duodenal ulcer.

Although tricyclamol decreased gastric motility, paradoxically gastric emptying became more rapid after giving the drug to a patient with partial gastrectomy. This seemed to be due to the extreme flaccidity of the stomach with greater dependence of the stoma, allowing barium to pour through at a very fast rate. Symptoms of "dumping" were not produced in this patient after taking a barium meal preceded by tricyclamol.

Side-effects sufficient to cause slight discomfort were observed in most of the patients in whom the effects of tricyclamol were studied.

\section{Summary}

A preliminary report is presented on the effects of a new parasympathetic blocking drug, tricyclamol chloride.
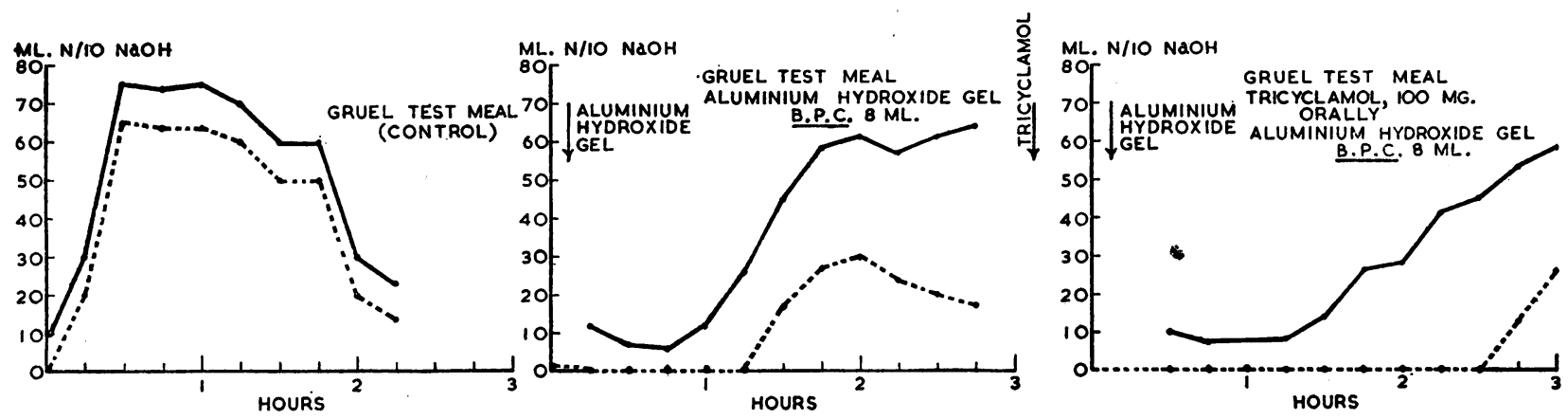

FIG. 3--Graphs showing effect of tricyclamol on the acidity of the gastric contents in comparison with aluminium hydroxide gel and a control. ....., Free acid. Total acid. 
The drug had a marked effect in reducing gastric motility and tone.

There was a smaller effect in reducing acidity of the gastric contents.

Tricyclamol prolonged the reduction of gastric acidity obtained by a dose of alkali.

We wish to thank Dr. J. D. Dow for the $x$-ray films, Professor W. R. Spurrell for providing facilities for the analysis of tes meals, and Messrs. Burroughs Wellcome and Co. for supplies of the tricyclamol chloride used in these investigations.

REPERENCES -

Douthwaite, A. H. (1939). Practitioner, 143, 461. - (1947). British Medical Journal, 2, 43. - and Thorne, M. G. (1951). Ibid., $1,111$.

James, A. H., and Pickering, G. W. (1949). Clin. Sci., 8. 181

\section{EFFECTS OF VALSALVA'S MANGUVRE ON THE NORMAL AND FAILING CIRCULATION}

E. P. SHARPEY-SCHAFER, F.R.C.P.

Professor of Medicine, London University

(From the Department of Medicine, St. Thomas's Hospital, London)

The Valsalva manœuvre (Valsalva, 1707), by producing a rise in intrathoracic pressure, causes an acute decrease in the effective filling pressure of the heart, with consequent changes in the stroke output. An analysis of continuous arterial pressure tracings in the normal subject performing the Valsalva manœuvre has shown that a decrease in pulse pressure occurs when intrathoracic pressure is raised, and that this is followed by a phase of raised diastolic pressure (the "overshoot"). The latter phase has been interpreted as a baroceptor response to the decreased pulse pressure of the former (Sharpey-Schafer, 1953)

Cases of heart failure might be expected to respond to the Valsalva manœuvre in a different manner, since a decrease in effective filling pressure produced by venesection may cause an increase in stroke output (Howarth et al., 1946). Preliminary observations, using continuous arterial pressure records, indicated that this was in fact so (Sharpey-Schafer, 1952).

This paper presents the accumulated data on normal subjects and observations on cases of heart failure of varied aetiology. The results have been interpreted in terms of baroceptor responses to acute changes in pulse pressure.

\section{Material and Methods}

Sixty-two subjects with a normal circulation and 63 cases of heart failure were studied. All the eases of heart failure were in sinus rhythm and had a jugular venous pressure raised from 2 to $25 \mathrm{~cm}$. above sternal angle level : 19 were cases of hypertensive heart failure, 9 had ischaemic heart disease, 21 had disease of the mitral or aortic valves, 7 had cor pulmonale (emphysema), 3 severe anaemia, 2 severe thyrotoxicosis, and there was 1 each of the following: primary pulmonary hypertension, pulmonary embolus, haemochromatosis, and chronic myocarditis.

Continuous arterial pressure records were obtained using capacitance manometers (Hansen, 1949), which were also employed for the measurement of intrathoracic pressure
(Dornhorst and Leathart, 1952). In some observations a differential manometer system was used (Lee et al., 1954), usually differentiating intra-arterial and intrathoracic pressures.

The Valsalva manœuvre was performed by blowing a mercury column to $40 \mathrm{~mm}$. $\mathrm{Hg}$ and maintaining it at that level for about 10 seconds. This was easily accomplished by patients with heart failure, however breathless, and by quite young children for a small monetary reward. The procedure is without risk in heart failure for reasons that will become apparent. All subjects were supine with the trunk raised to 45 degrees with the horizontal.

\section{Results}

The difference in response between normal subjects and cases of heart failure was conspicuous Figs. 1, 2, and 3).

\section{Factors Affecting Response in the Normal Subject}

When the intrathoracic pressure is suddenly raised to $\mathbf{4 0}$ $\mathrm{mm}$. $\mathrm{Hg}$ this pressure is rapidly transmitted to all the arteries and to those veins without valves. The immediate supply pressure to many internal organs, such as the brain, is therefore essentially unaltered. In skin and muscle, however, the venous valves shut and initially the arteriovenous supply pressure is raised by approximately the same amount as the intrathoracic pressure. Since the blood-flow to a part depends on supply pressure and the calibre of the arterioles,

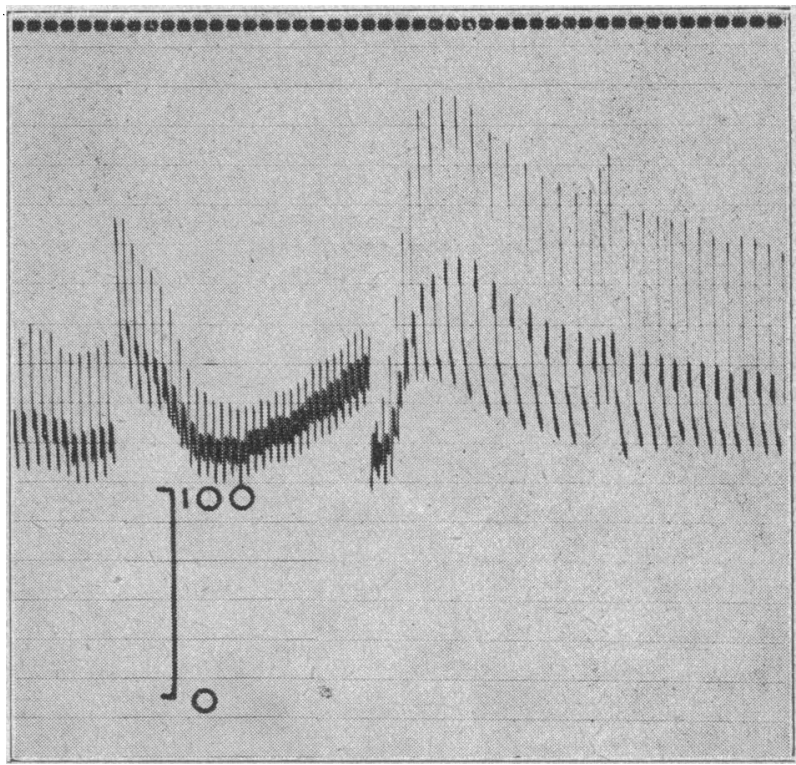

FIG. $1 . \leftarrow$ Continuous arterial record showing cffect of Valsalva manœuvre in normal subject. Calibration in $\mathrm{mm}$. $\mathrm{Hg}$ and time marker in seconds in this and subsequent records.

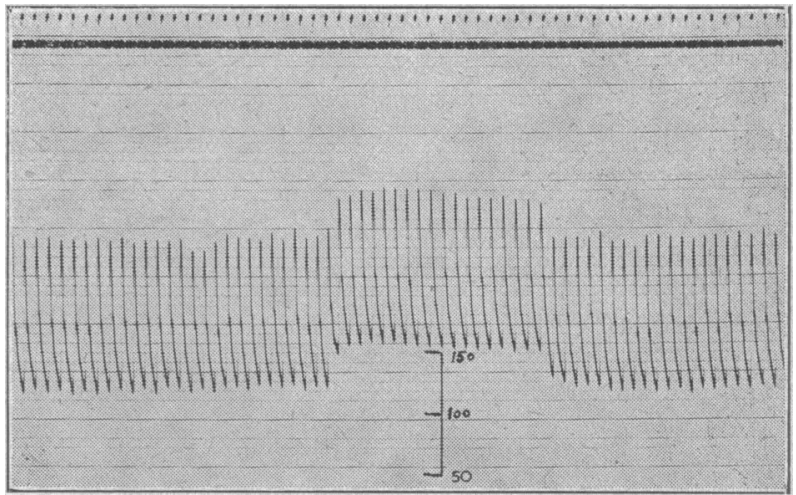

Fig. 2.-Hypertensive heart failure, showing effect of Valsalva manœuvre on arterial blood pressure. 